\title{
Indirect consequences of COVID-19 on people's lives. Findings from an on-line survey in France, Italy and Spain
}

\author{
Bruno Arpino $^{1}$, Marta Pasqualini ${ }^{2}$, Valeria Bordone $^{3}$, Aïda Solé-Auró ${ }^{2}$
}

1. Department of Statistics, Computer Science, Applications, University of Florence Viale Morgagni, 59, 50134 Firenze, Italy. Email: bruno.arpino@unifi.it

2. Department of Political and Social Sciences, Universitat Pompeu Fabra, C/ Ramon Trias Fargas, 2527, 08005, Barcelona, Spain.

3. Department of Sociology, University of Vienna, Rooseveltplatz 2, 1090 Vienna, Austria. 


\begin{abstract}
The COVID-19 pandemic has limited individuals' possibility to meet and socialize with others due to the state of emergency restrictions to movements, events and relations imposed in different countries. Most shops and restaurants have been closed and some economic activities have been seriously damaged. This significant disruption may have contributed to a deterioration of people's mental health on top of other negative consequences of the pandemic.

To better understand the indirect consequences of the COVID-19 outbreak on people's lives we have designed the intergen-COVID online survey
\end{abstract} (https://sites.google.com/unifi.it/intergen-covid), carried out in France, Italy and Spain between the $14^{\text {th }}$ to the $24^{\text {th }}$ of April 2020. Quota sampling on the population 18-plus and post-stratification weights were used to achieve the alignment between the sample $(\mathrm{N}=9,056)$ and the total population on important socio-demographic characteristics.

We collected information on four key domains of individuals' lives: intergenerational (and other type of) relationships (physical and non-physical; means of communication; frequency, etc.); living arrangements; mental health; events experienced during the lockdown (e.g., income loss, death of relative/friend due to COVID-19, worsened partner relationships, time spent with family); intentions for the future 3 years (e.g., fertility, living parental home, marriage, cohabitation, divorce/separation, retirement).

In this paper we provide the main results from this survey, focusing on the first three domains abovementioned. The fourth domain consists of questions applicable to different subgroups of the population and will be analyzed in separate papers. We show that, despite the general reduction of physical contacts, with low educated people reporting a lower reduction in all kinds of physical contacts, non-physical contacts have significantly increased, especially among women. About $50 \%$ of respondents felt sad or depressed more often than usual during the lockdown, but mental health deterioration was found to be heterogeneous and vary with respondents' age, gender and country. Job and income loss, and worsening of relationships quality were other negative consequences often experienced during the lockdown, especially by younger individuals. Finally, although maintaining physical distance, during the lockdown people have experienced a high level of social connection, emotional support and practical help. 


\section{Introduction}

The outbreak of the SARS-CoV-2 virus and the associated coronavirus disease 2019 (COVID19) originated in China in December 2019 and quickly spread across the globe causing more than 9 million cases and about half a million deaths up to June 25, 2020 (WHO 2020). The necessity to contain the spread of the SARS-CoV-2 virus has raised important challenges for governments and societies that adopted different policy measures. As physical contacts are a necessary condition for SARS-CoV-2 transmission (Huang et al., 2020; Peeri et al., 2020), under the coronavirus state of alarm people have been advised to keep 'distance' from each other and stay at home (Kumar, 2020). To ensure that physical distance was respected, some governments imposed different types of lockdown measures (such as prohibition of public events, the closure of schools, universities and non-essential workplaces, limiting public transportation, travel and movement restrictions and limiting physical interactions). France, Italy and Spain were particularly damaged by the virus (Ceylan, 2020) and were among the first countries in Europe to lock down completely to reduce the contagion.

Social scientists have been focusing on understanding the unequal spread and lethality COVID-19 across countries and age groups (Arpino et al., 2020; Dowd et al., 2020; Esteve et al., 2020). The indirect impact of the COVID-19 outbreak, e.g. due to lockdown restrictions, are also expected to be serious and broad in terms of life domains involved including fertility plans (Luppi et al, 2020) and economic conditions (Bonaccorsi et al, 2020). According to Evandrou et al. (2020), the lockdown has brought disruption to daily life for the whole population and measures adopted to contain the virus are likely to leave their mark by producing detrimental effects on financial, relational, physical and psychological domains. It has also been argued that vulnerabilities to COVID-19 are expected to be heterogeneous within the population, so that the short- and long-term consequences of the COVID-19 crisis are likely to vary (Mikolai et al, 2020).

The unprecedent situation created by the outbreak responses makes urgent to understand how lockdown measures have affected individuals' lives. To this end, we have designed an online survey administered by the Lucid company on a total sample of 9,186 individuals living in Italy, Spain and France conducted in April 2020. The survey targeted people aged 18+. We used quota sampling and post-stratification weights to better achieve the alignment between the sample and the population on the distribution of key socio-demographic characteristics.

In this paper we aim at contributing to shed light on the indirect consequences of COVID19 on people's lives posing particular attention on social relationships, mental health, but also on other events, such as income and job loss and having experienced the death of relatives or friends due to COVID-19. Moreover, we examine whether the lockdown had an unequal impact on 
groups of the population defined by key socio-demographic characteristics, i.e., age, gender and education, as well across the three considered countries.

\section{Data and Methods}

We carried out a survey named intergen-COVID. The data have been collected through the online market survey platform Lucid, that offers the opportunity to purchase samples for survey research, showing to produce high quality, representative samples (Coppock and McClellan, 2019). More specifically, Lucid recruits respondents through a three steps process (Callaghan, et al., 2019): (1) suppliers collect lists of potential survey respondents and invite them to take part in the survey; (2) Lucid administers a general set of variables such as gender, age, region, educational attainment and income to be submitted to individuals who agreed to participate; (3) based on information collected in step (2), Lucid invites individuals to take part to the survey using quota sampling, namely splitting up the population into as many sub-sets as the characteristics we want to observe and in a way that the proportion of each sub-set in the sample is the same as in the population. This procedure ensures that the final sample is nearly equal to the country benchmark.

Through the intergen-COVID survey we collected information on four key domains of individual's life: intergenerational (and other type of) relationships (physical and non-physical; means of communication; frequency, etc.); living arrangements; mental health; events experienced during the lockdown (e.g., income loss, death of relative/friend due to COVID-19, worsened partner relationships, time spent with family); intentions for the future 3 years (e.g., fertility, living parental home, marriage, divorce, retirement). The survey was carried out in each country in the respective official language. Most of the questions were drawn from validated European surveys ${ }^{1}$ and the full English questionnaire is reported in Appendix A.

The target sample was of 3,000 individuals per country. Data were collected between April, $14^{\text {th }}$ and April, $24^{\text {th }}$ 2020. Although the sampling was not probabilistic, Lucid targeted representativeness on age, gender, education and region of residence within each country. Moreover, we used post-stratification weights to minimize deviations from the benchmark population. The post-stratification weights are obtained by following the European Social Survey procedure (ESS, 2014). More specifically, this procedure adjusts the weights in such a way that they replicate the distribution of three population distributions (so called Control Data): one for the cross-classification of age and gender (AG), one for the cross-classification of age and education $(\mathrm{AE})$ and one for the region of residence $(\mathrm{R})$. The population distributions of the

\footnotetext{
${ }^{1}$ Specifically: European Social Survey (ESS), Generations \& Gender Survey (GGS) and Survey of Health, Ageing and Retirement in Europe (SHARE).
} 
adjusting variables are obtained from the national statistical offices (respectively: INSEE for France, ISTAT for Italy and INE for Spain and). Unavailable population statistics from the national statistics offices were obtained using EUROSTAT data. The weighting procedure used has the great advantage to allow the achievement of the alignment between the distribution of key socio-demographic characteristics in the sample and that in the known population.

The method of calculating post-stratification weights was based on the STATA package “ipfweight” (Bergmann, 2011). More specifically, this method generates weights through iterative procedure that performed stepwise adjustments of the weights until it has achieved the margins of Control Data, as defined by the three weighting dimensions defined above (AG, $\mathrm{AE}$, R). The procedure of deriving post-stratification weights has been applied country-by-country.

The following section reports descriptive statistics on the first three domains of the intergen-COVID survey listed above. Estimates are obtained using the post-stratification weights and are presented by age, gender, education and country. As for age we generally consider five age groups: $18-25,26-35,36-49,50-64,65+$. Gender is a dummy variable taking value 1 if respondent was a woman and 0 otherwise ${ }^{2}$. Education is re-coded into three categories based on the International Standard Classification of Education, where a "low" educational level is defined as below secondary education, "medium" as up to high-school and "high" refers to a university education or above. Finally, country is a 3-level categorical variable indicating the country where respondents were living at the time of the survey (France, Italy or Spain).

\section{Results}

\section{1 (Intergenerational) Relationships during the lockdown}

Figure 1 reports weighted descriptive statistics of the decreased level of physical contacts during the COVID-19 pandemic by age (Panel a), gender (Panel b), country (Panel c) and education (Panel d). Overall, almost $75 \%$ of the respondents reported a reduction of physical contacts during the lockdown. Although we did not find noticeable differences by gender and age, we observe that low educated people reported a lower reduction in all kinds of physical contacts compared with both medium and high educated people. Finally, a higher proportion of individuals living in Spain and Italy reported a decrease in all types of physical contacts (about $80 \%$ ) compared with those living in France (63\%).

Intergenerational physical contacts have been reduced particularly among younger adults aged 26-35 (57\%) and 36-49 (56\%) compared to the oldest one (48\%). This could be due to the need or wish to avoid contacts of grandchildren with older people and it is supported by looking

\footnotetext{
${ }^{2}$ Gender was assessed in the questionnaire as follow: male, female, other. However, since the number of respondents indicating "other" as response were few $(\mathrm{N}=56 ; 0.61 \%$ of the sample), we dropped them from the study.
} 
at individuals in this age range with at least one parent alive and distinguishing between respondents with and without children (Figure 2). Figure 2 shows weighted descriptive findings of decrease in physical contacts between respondents and their parents by own parenthood status: a) by gender and age groups (26-35 vs 36-49) and b) by country and age groups (26-35 vs 3649). Overall, we notice that a reduction of physical contacts with parents was less frequent among childless respondents, especially among men and in the youngest age category considered (2635). A cross-country comparison (Panel b) shows similar percentages of individuals that reduced physical contacts with their parents among childless respondents when comparing France, Italy and Spain; instead, among parents we observe a higher prevalence of individuals that reduced contacts with their own parents in Italy and Spain, where intensive grandparental childcare is more common. The reduction of contacts between individuals with children and their parents may have followed the initial hypothesis that children were "superspreaders" of SARS-CoV-2, like they are for other respiratory viruses, which was then not supported by the evidence (Ludvigsson, 2020).

Yet, while most of the individuals reported a reduction in physical contacts, non-physical contacts have increased in all countries and for the sociodemographic characteristics considered (Figure 3). Particularly, over 50\% of the respondents in each age group reported increased nonphysical intergenerational contacts, with young adults reporting it in the highest proportion (61\% of respondents aged 26-35; Panel a). With regard to gender (Panel b), we found that $75 \%$ of men and $78 \%$ of women reported an increase in all kind of non-physical contacts. In a cross-country comparison (Panel c), Spain is the country showing the highest prevalence of respondents who increased their non-physical intergenerational contacts. Low educated respondents were those reporting in a lower prevalence an increase of intergenerational non-physical contacts (47\% vs. $57 \%$ and $56 \%$ of those with a medium and high level of education, respectively; Panel d). Overall, findings on non-relatives, other relatives and all type of relationships were strongly in line with those commented above.

More specifically, $48 \%$ of the respondents reported an increase in non-physical contacts with friends (Figure 4, Panel a). Among those aged 65+, an increased in non-physical contacts with children was reported by more than $45 \%$ of respondents and an increase in non-physical contacts with grandchildren by about $30 \%$ of them. Men and women reported similar percentages of increased relationships with children, grandchildren and parents while a slightly higher proportion of women reported to have increased - during the COVID19 pandemic - their nonphysical contacts with grandparents (11\% vs $9 \%$ of men), other relatives (44\% vs 39\%) and friends ( $52 \%$ vs $45 \%$ ). Overall, Spain is the country with the highest prevalence of respondents reporting any kind of increased non-physical contacts (82\% vs $73 \%$ in Italy and $71 \%$ in France). 
Figure 5 shows changes in non-physical contacts by video calls (Panel a, b), social media (Panel c, d) or instant messages (Panel e, f) by age groups and education level. Although the clear age gradient of having never used video calls (Panel a), social media (Panel c) and instant messages (Panel d) - reported by about $30 \%$ of $65+$ vs $8 \%$ of $18-25$ - we notice that more than half $(55 \%)$ of the respondents showed an increase in video calls and instant messaging. Overall, $73 \%$ of the respondents increased daily non-physical contacts, especially women (75\%).

\subsection{Mental health during the lockdown}

About $47 \%$ of respondents reported to have felt sad or depressed more often than usual during the lockdown (Figure 6) revealing a great heterogeneity by age, gender and country. Depression and feeling of sadness were relatively more frequent among individuals aged 26-35 in all three countries (Panel a). Moreover, a higher prevalence of reported depressive symptoms were found for women as compared to men (58\% vs. 46\%) in Spain (Panel b) and among medium and high educated respondents as compared to their lower educated counterparts both in Italy (respectively: $49 \%$ and $44 \%$ vs. $41 \%$ ) and Spain (53\% and $48 \%$ vs. $38 \%$; Panel c). Similarly, about $35 \%$ of respondents declared to have felt lonely more often than usual during the pandemic and in all three countries the prevalence of respondents who felt lonely was highest in the age group 26-35 (between 39 in France and 44\% in Spain), although a non-negligible percentage of respondents aged 18-25 also reported to have felt lonely more often than usual during the lockdown (up to $38 \%$ in Italy). A wider gender gap was found in Italy with $40 \%$ of women (vs $29 \%$ of men) reporting to have felt lonely more often than usual (Panel e). Finally, although in Italy similar percentages of loneliness were reported across educational levels, inconsistent results were found for Spain and France in this respect (Panel f).

\subsection{Events experienced during the lockdown}

Figure 7 shows weighted descriptive statistics for other important consequences of the COVID19 pandemic that individuals may have experienced. Apart from the expected reduction in physical exercise, also income, job and quality of relationships have been significatively affected during the pandemic. A noticeable variation by age has been observed (Panel a), especially with regard to income loss. Indeed, weighted descriptive statistics show that it was particularly frequent among individuals aged 26-49 (about 40\%). Moreover, it is interesting to note that 31\% of respondents aged 18-25 experienced difficulties in studying/working from home. Overall, men and women did not significantly differ in terms of main reported consequences of COVID-19 on daily life (Panel b) except for income loss which was reported by a slightly higher proportion of women $(33 \%$ vs $29 \%)$. 
We detect a reduction of physical activity in each country (Panel c). Interestingly, a reduction in daily life domain was among the most reported with the highest percentage found in Spain (63\%), followed by Italy (47\%) and France (40\%) according to where the measures to limit outdoor sport activities have been the most restrictive. The second most commonly reported domain of change was the income loss which has been respectively reported by $35 \%$ of respondents in Italy and Spain and by $24 \%$ in France. On the other hand, a high percentage of respondents reported to have spent more time with their family. Specifically, it has been reported by $44 \%$ of respondents in Italy, $36 \%$ in Spain and $21 \%$ in France. However, overall, $11 \%$ and $13 \%$ of respondents reported worsened relationships with partner and other people, respectively. With regard to education (Panel d), we detect that events experienced during the lockdown were - overall - less reported by lower educated people compared with both, middle and highly educated.

\subsection{Help and support received during the lockdown}

Overall, about $53 \%$ of respondents reported to have received some kind of help from others during the lockdown (Figure 8). Panel a presents weighted descriptive findings by age groups showing that a higher proportion of younger respondents reported to have received emotional support compared with the older generations, with the lowest percentage reported by the age group 50-65+ (about 37\%). Moreover, we notice that older generations were also those showing the lowest percentage of received financial help (2\% among 65+).

A wide gender gap was found for emotional support which was reported by $38 \%$ of men and $50 \%$ of women (Panel b). With regard to differences across countries (Panel c), we found the highest percentage of emotional support received in Spain (53\%), followed by France (41\%) and Italy (37\%). Finally, an educational gradient has been found for emotional support which was most frequently reported by higher educated groups (Panel d).

\section{Conclusion}

The significant impact of the COVID-19 pandemic on mortality and morbidity is already evident. This paper has focussed on the indirect consequences of the COVID-19 outbreak due to the policy responses, that although necessary to contrast the diffusion of the virus, have imposed restrictions to contacts, movements and economic activities. These indirect effects are expected to be substantial and broad in terms of involved life domains. To understand the indirect consequences of COVID-19 outbreak, we presented results from an online survey conducted in France, Italy and Spain in April 2020. This survey provide timely insights on how the outbreak responses are affecting individuals lives in four domains: intergenerational (and other type of) 
relationships (physical and non-physical; means of communication; frequency, etc.); living arrangements; mental health; events experienced during the lockdown (e.g., income loss, death of relative/friend due to COVID-19, worsened partner relationships, time spent with family); intentions for the future 3 years (e.g., fertility, living parental home, marriage, cohabitation, divorce/separation, retirement).

Our intergen-covid online survey was conducted in the three European countries that first implemented nationwide lockdown measures in March 2020. Data have been collected between the $14^{\text {th }}$ to the $24^{\text {th }}$ of April 2020 , i.e. about 1 month after the entry into force of the restrictive measures. Quota sampling on the population 18+ and post-stratification weights were used to achieve the alignment between the sample $(\mathrm{N}=9,056)$ and the total population on important socio-demographic characteristics.

In this paper we report the main descriptive results from the intergen-covid survey. Additional findings and publications based on this survey will be listed on the dedicated website: https://sites.google.com/unifi.it/intergen-covid.

The analyses in this paper generally point at considerable effects of the lockdown on relationships, mental health, income and employment. We also found that these consequences vary according to individual characteristics and among the considered countries.

We show that, as a consequence of the lockdown, the great majority of individuals in all countries reduced physical contacts. Both intergenerational and other types of contacts have been reduced. Intergenerational physical contacts have been limited particularly between younger individuals with children and their parents, suggesting the need or wish to avoid contacts between children and their grandparents. This is also consistent with the finding that a higher prevalence of reduced contacts with parents was found among individuals with children in Italy and Spain, where intensive grandparental childcare is more common.

On the other hand, our results also demonstrate a high degree of interpersonal connectedness and solidarity. In fact, the reduction in physical contacts has been accompanied by a similar increase in non-physical relations. Therefore, physical distancing has been compensated by social contacts at a distance. The increase in non-physical contacts was particularly evident in Spain, the country that experienced the most stringent lockdown measures among the three considered and where physical contacts were reduced the most. Men and women reported similar percentages of increased relationships with children, grandchildren and parents while a slightly higher proportion of women reported to have increased their non-physical contacts with grandparents, other relatives and friends. We also document an increase in digital communications: more than half of the respondents reported an increase in video calls and use of instant messaging to keep contacts at a distance. 
Not only non-physical contacts have increased during the lockdown; a considerable percentage of individuals also received emotional support and practical help during this period, with strong heterogeneities within and between countries. Received emotional and financial support was lowest among individuals aged 65+. Emotional support was also more likely to be received by women and individuals with higher levels of education. Comparing the three countries we analyzed, the highest percentage of emotional support received was in Spain.

The impact of lockdown measures on mental health is worrying. About $50 \%$ of respondents felt sad or depressed more often than usual during the lockdown. Mental health deterioration was found to meaningfully vary by age, gender and country. Increased feelings of depression and sadness were relatively more frequent among individuals aged 26-35, among women (especially in Spain), and among medium and high educated people.

Finally, our results demonstrate that other frequently reported significant negative impacts concern the economic sphere and labor market, especially for younger individuals. About $40 \%$ of individuals aged 26-49 reported an income loss and almost $10 \%$ of them lost their job during the lockdown. These negative consequences were particularly strong in Spain and Italy, and slightly more often experienced by women than men.

All in all, our study demonstrates strong and broad negative consequences of the lockdown on mental health, income and employment. On the other hand, while physical contacts have been considerably reduced, solidarity has been maintained by increasing non-physical contacts and by provision of emotional and instrumental help. 


\section{References}

Arpino, B., Bordone, V., \& Pasqualini, M. (2020). No clear association emerges between intergenerational relationships and COVID-19 fatality rates from macro-level analyses. Forthcoming in Proceedings of the National Academy of Sciences (PNAS).

Bergmann, M. (2011). ipfweight: Stata module to create adjustment weights for surveys. Statistical Software Components S457353, Department of Economics, Boston College. http://econpapers.repec.org/software/bocbocode/s457353.htm.

Bonaccorsi, G., Pierri, F., Cinelli, M., Flori, A., Galeazzi, A., Porcelli, F., ... \& Pammolli, F. (2020). Economic and social consequences of human mobility restrictions under COVID-19. Proceedings of the National Academy of Sciences (PNAS), first published June 18, 2020 https://doi.org/10.1073/pnas.2007658117.

Callaghan, T., Motta, M., Sylvester, S., Trujillo, K. L., \& Blackburn, C. C. (2019). Parent psychology and the decision to delay childhood vaccination. Social science \& medicine, 238, 112407.

Ceylan, Z. (2020). Estimation of COVID-19 prevalence in Italy, Spain, and France. Science of The Total Environment, 729, 138817.

Coppock, A., \& McClellan, O. A. (2019). Validating the demographic, political, psychological, and experimental results obtained from a new source of online survey respondents. Research \& Politics, 6(1), 2053168018822174.

Dowd, J. B., Rotondi, V., Andriano, L., Brazel, D. M., Block, P., et al. (2020). Demographic science aids in understanding the spread and fatality rates of COVID-19. Proceedings of the National Academy of Sciences (PNAS), First published April 16, 2020, https://doi.org/10.1073/pnas.2004911117.

European Social Survey (ESS 2014). Documentation of ESS Post-Stratification Weights. www.europeansocialsurvey.org, 25th April 2014

Esteve, A., Permanyer, I., Boertien, D., \& Vaupel, J. W. (2020). National age and coresidence patterns shape COVID-19 vulnerability. Proceedings of the National Academy of Sciences (PNAS), first published June 23, 2020 https://doi.org/10.1073/pnas.2008764117.

Evandrou, M., Falkingham, J., Qin, M., \& Vlachantoni, A. (2020, June 24). Older and 'staying at home' during lockdown: informal care receipt during the COVID-19 pandemic amongst people aged 70 and over in the UK. https://doi.org/10.31235/osf.io/962dy

Huang, C., Wang, Y., Li, W., \& et al. (2020) Clinical features of patients infected with 2019 novel coronavirus in Wuhan, China. Lancet, 395, 497-506.

Kumar, S. (2020). Corona Virus Outbreak: Keep Physical Distancing, Not Social Distancing. (March 28, 2020). Available at SSRN: https://ssrn.com/abstract=3568435. 
Ludvigsson, J. F. (2020). Children are unlikely to be the main drivers of the COVID-19 pandemic-a systematic review. Acta Paediatrica. First published: 19 May 2020 https://doi.org/10.1111/apa.15371.

Luppi, F., Arpino, B., \& Rosina, A. (2020). The impact of COVID-19 on fertility plans in Italy, Germany, France, Spain and UK. SocArXiv. https://osf.io/preprints/socarxiv/wr9jb/.

Mikolai, J., Keenan, K. \& Kulu, H. (2020). Intersecting household level health and socioeconomic vulnerabilities and the COVID-19 crisis: An analysis from the UK. SSM $\begin{array}{lllll}\text { Population Health. } & \text { Available } & \text { July } & \end{array}$ https://doi.org/10.1016/j.ssmph.2020.100628.

Peeri, N.C., Shestha, N., Rahman, M.S., \& et al. (2020) The SARS, MERS and novel coronavirus (COVID-19) epidemics, the newest and biggest global health threats: what lessons have we learned? International Journal of Epidemiology. In press.

World Health Organization (WHO 2020) Coronavirus disease 2019 (COVID-19): Situation Report n. 157. https://www.who.int/docs/default-source/coronaviruse/situationreports/20200625-covid-19-sitrep-157.pdf?sfvrsn=423f4a82_2. (Accessed on June 26, 2020). 


\section{Figures}

Figure 1. Decrease of physical contacts during the COVID-19 pandemic by country and socio-demographic characteristics

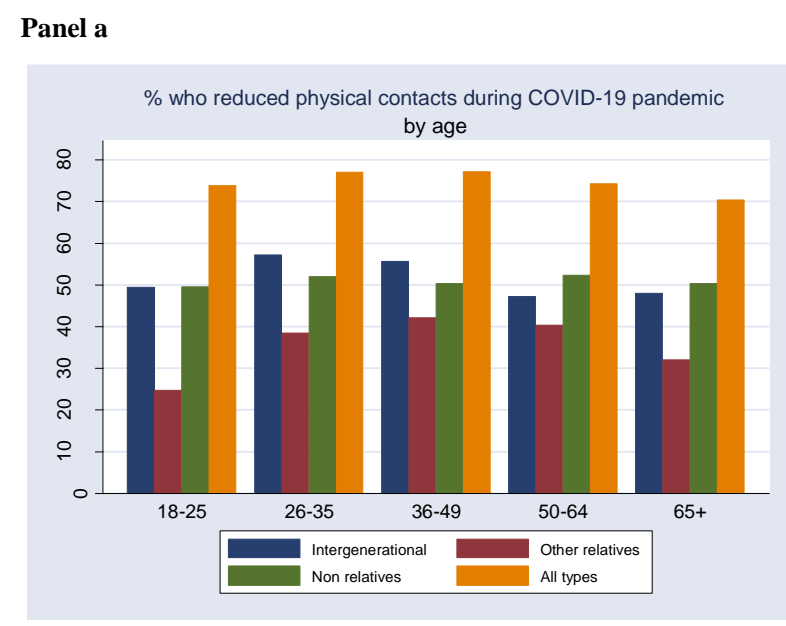

Panel b

Panel c
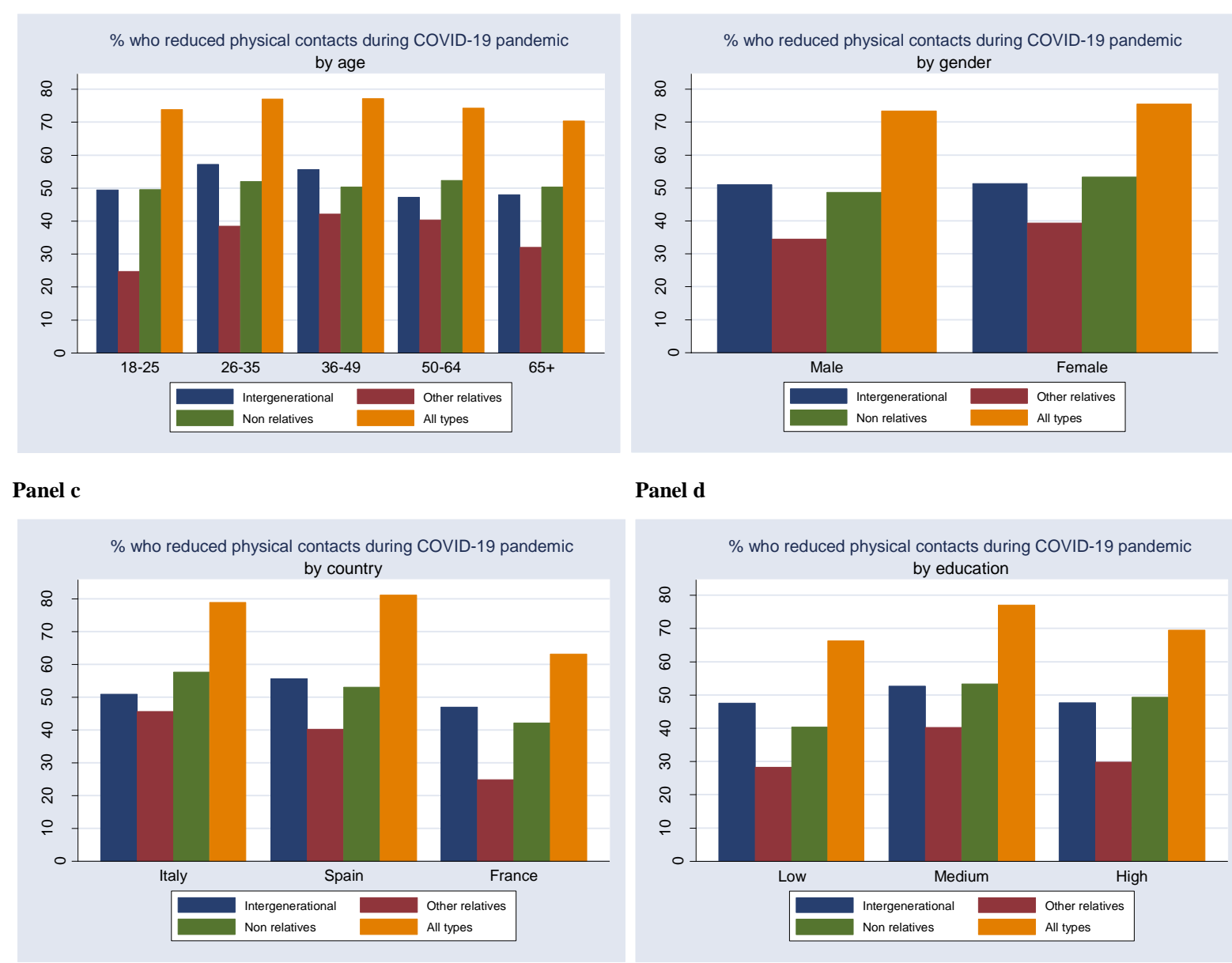

\section{Panel d}

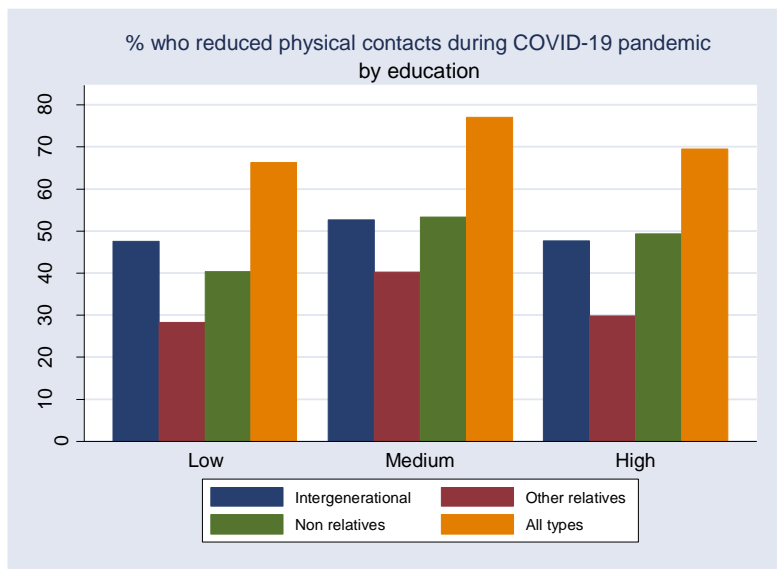

Note: $\mathrm{N}=9,056$. Post-stratification weights are used.

Source: Intergen-covid online survey. Data were collected between14-24 April 2020. 
Figure 2. Decrease of physical contacts during the COVID-19 pandemic with parents by parenthood, country, and demographic characteristics

Panel a

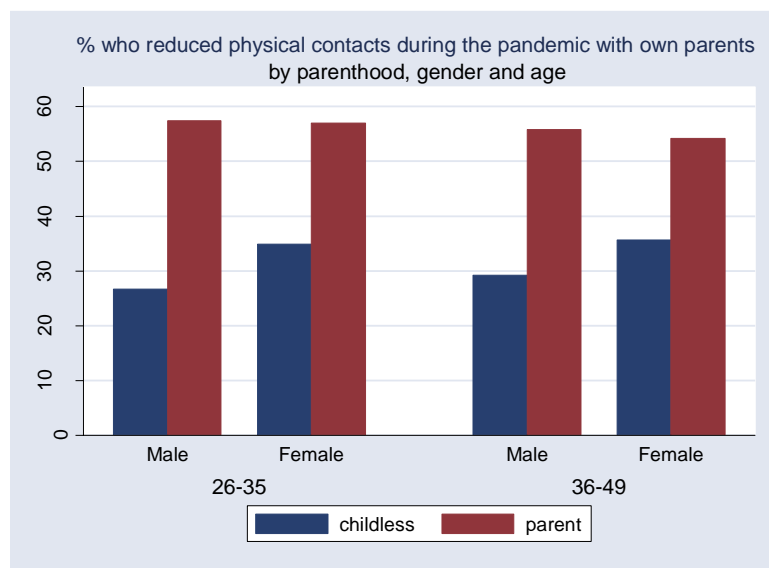

Panel b

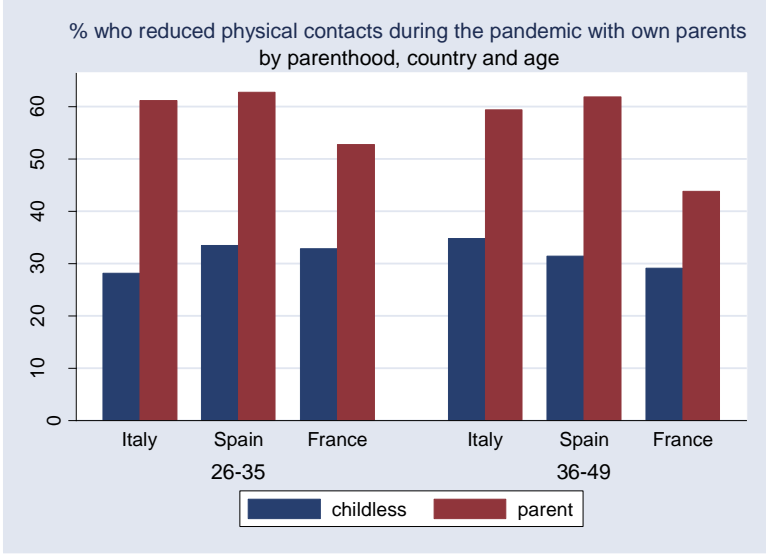

Note: $\mathrm{N}=9,056$. Post-stratification weights are used.

Source: Intergen-covid online survey. Data were collected between14-24 April 2020. 
Figure 3. Increase of non-physical contacts (e.g. on the phone, WhatsApp, Facebook) during the COVID-19 pandemic by country, socio-demographic characteristics

Panel a

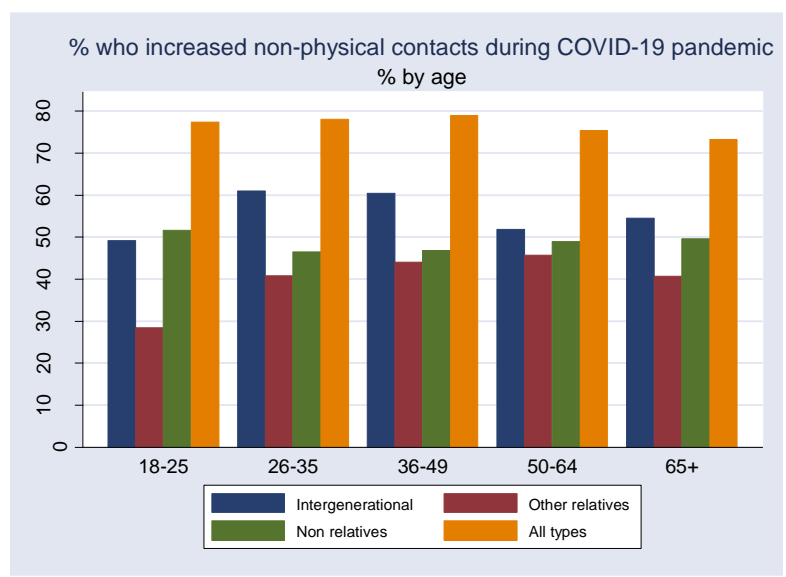

Panel c

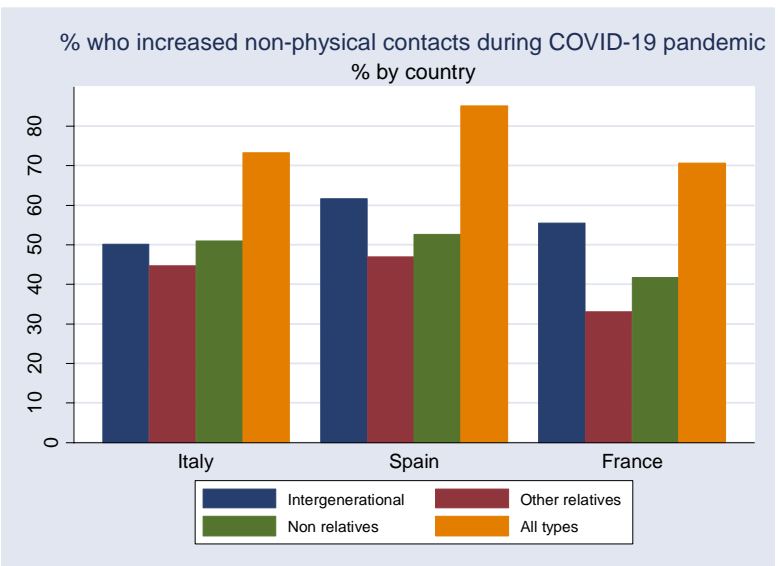

Panel b

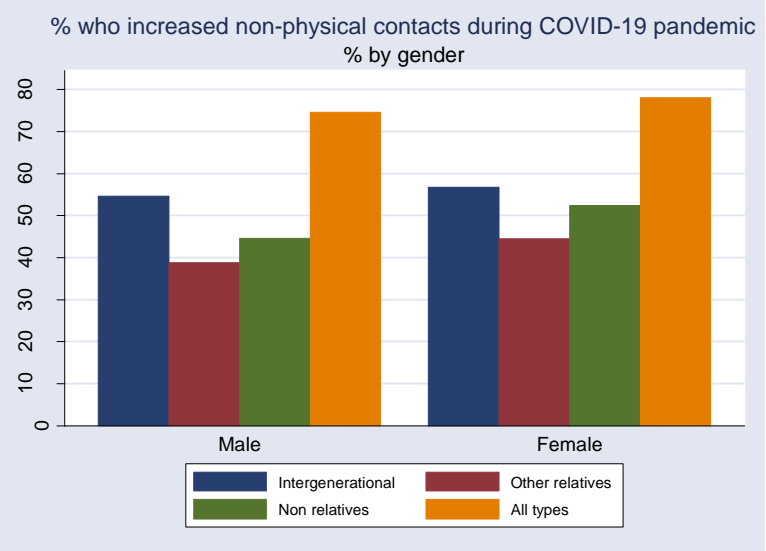

Panel d

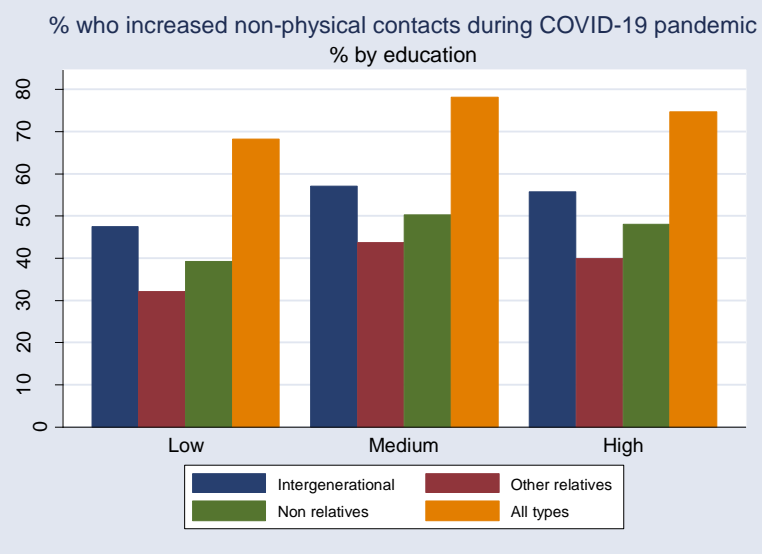

Note: $\mathrm{N}=9,056$. Post-stratification weights are used.

Source: Intergen-covid online survey. Data were collected between14-24 April 2020. 
Figure 4. Person with whom increased non-physical contacts (e.g. on the phone, WhatsApp, Facebook) during the COVID-19 pandemic by country, socio-demographic characteristics, and frequency

Panel a

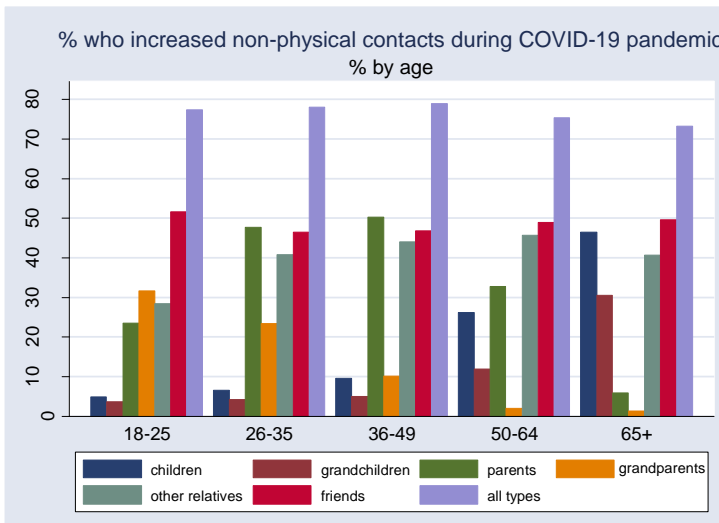

Panel c

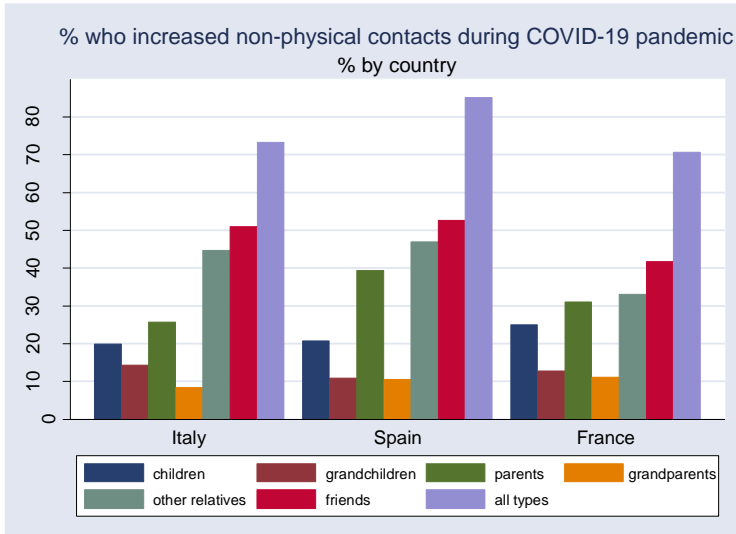

Panel e

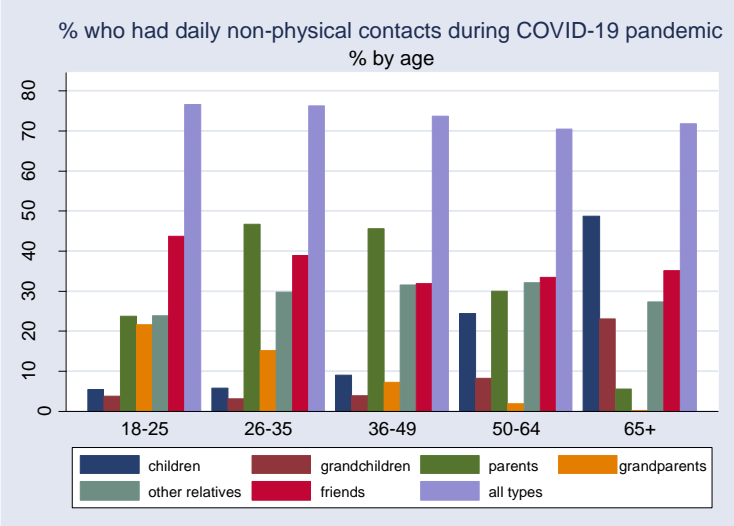

Panel b

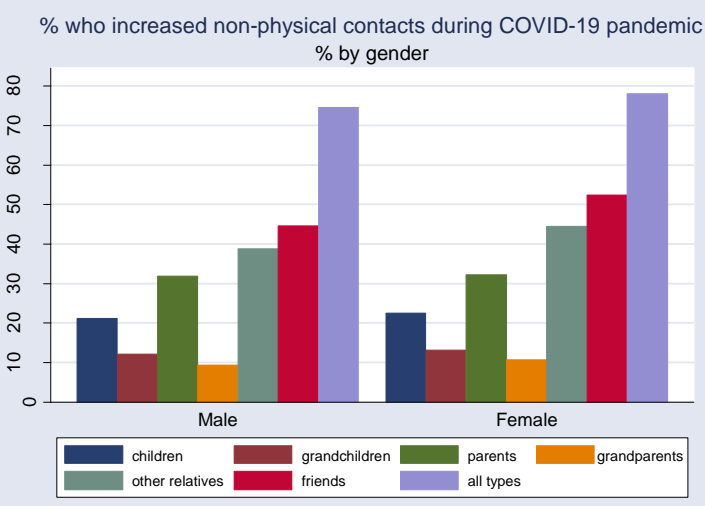

Panel d

$\%$ who increased non-physical contacts during COVID-19 pandemic $\%$ by education

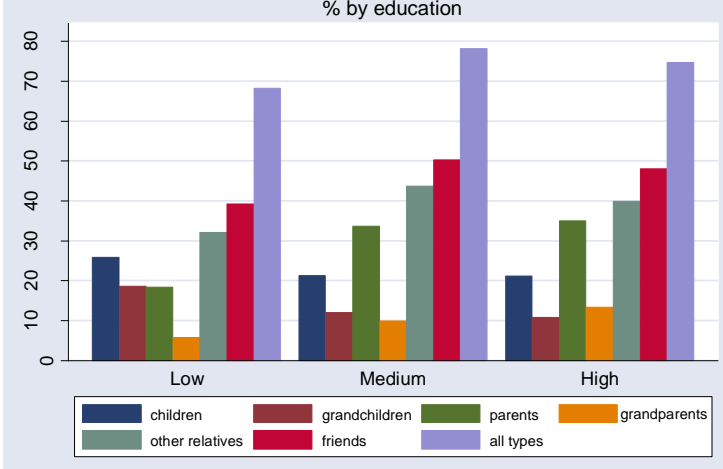

Panel f

$\%$ who had daily non-physical contacts during COVID-19 pandemic $\%$ by gender

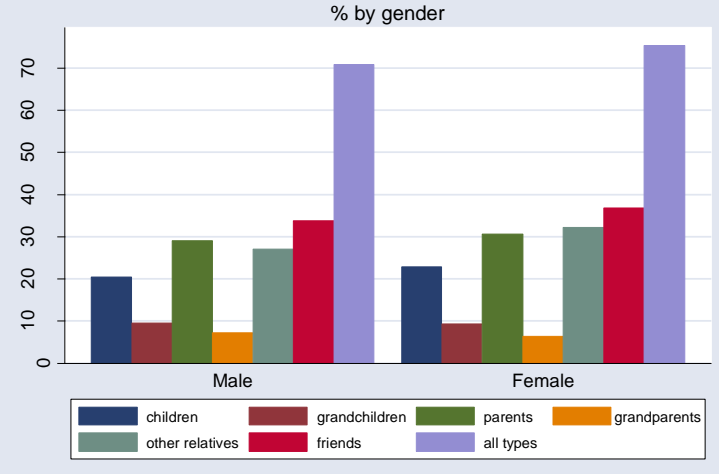


Panel g

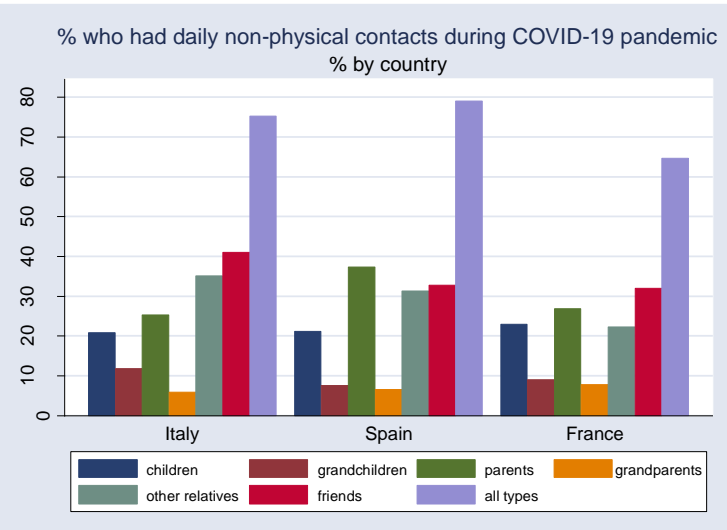

Panel h

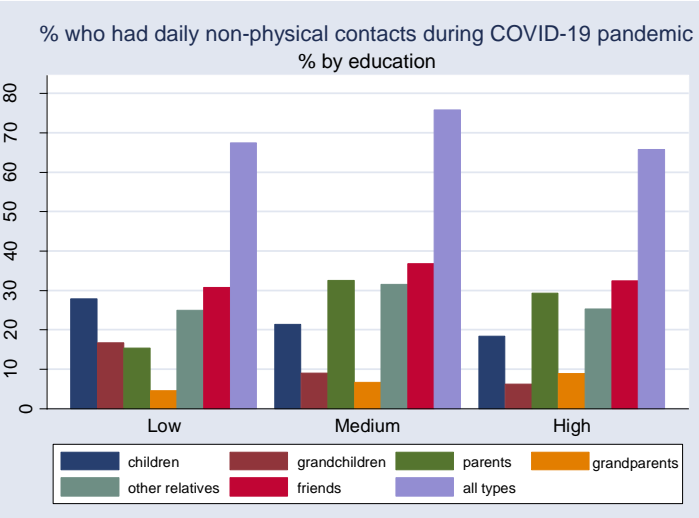

Note: $\mathrm{N}=9,056$. Post-stratification weights are used.

Source: Intergen-covid online survey. Data were collected between14-24 April 2020.

16 
Figure 5. Changes in frequency of non-physical contacts during the COVID-19 pandemic by type of contacts (i.e., on the phone, WhatsApp, Facebook), age, country, and education

Panel a

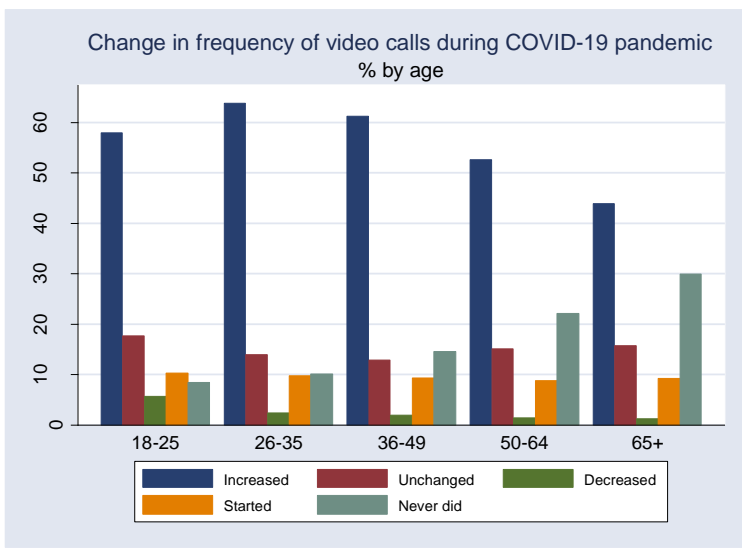

Panel c

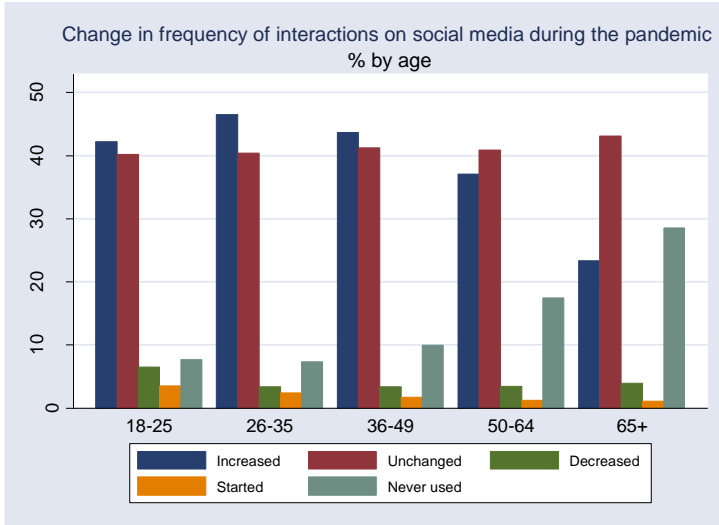

Panel e

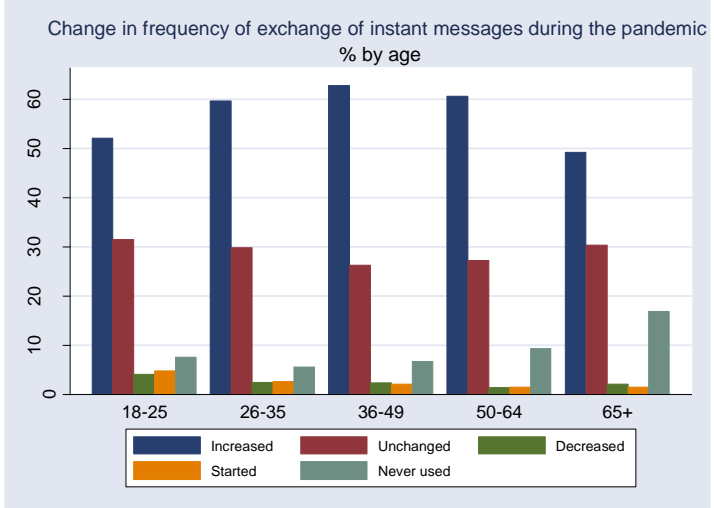

Panel b

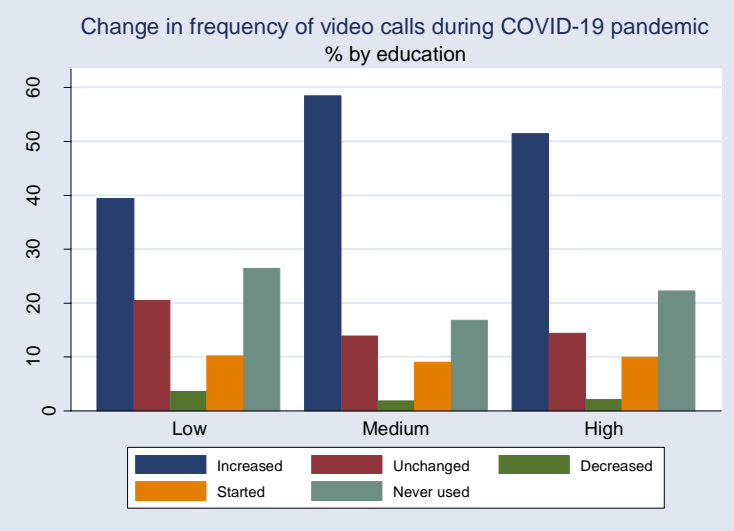

Panel d

Change in frequency of interactions on social media during the pandemic $\%$ by education

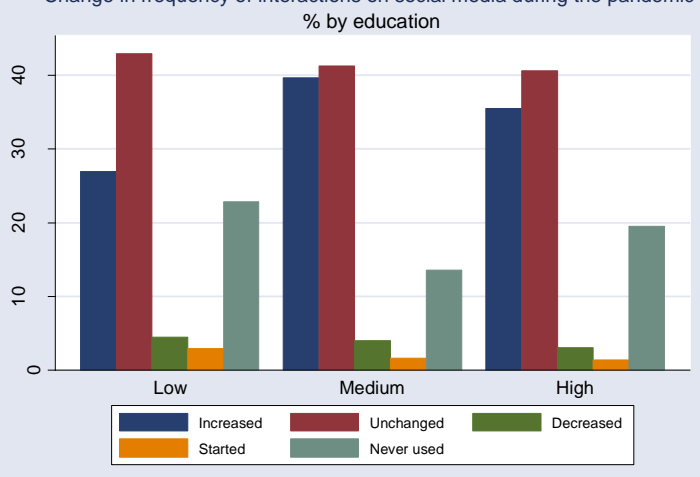

Panel f

Change in frequency of exchange of instant messages during the pandemic $\%$ by education

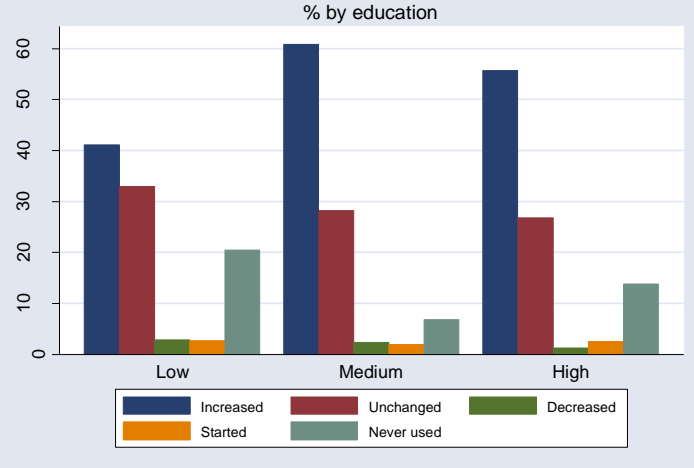

Note: $\mathrm{N}=9,056$. Post-stratification weights are used.

Source: Intergen-covid online survey. Data were collected between14-24 April 2020. 
Figure 6. Mental health during the COVID-19 pandemic by country, demographic and socioeconomic characteristics

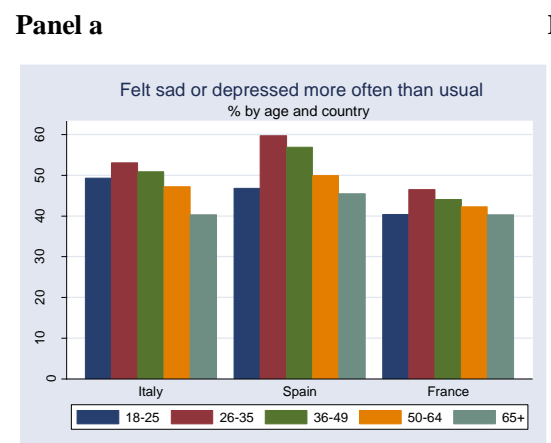

Panel b

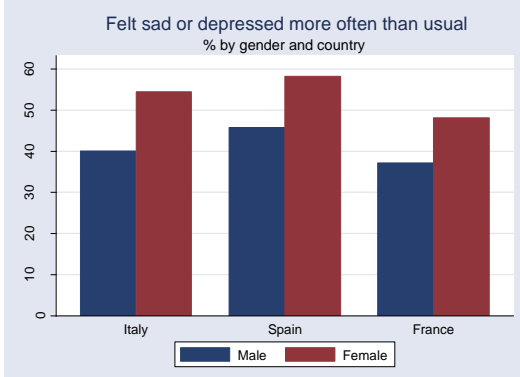

Panel e
Panel c

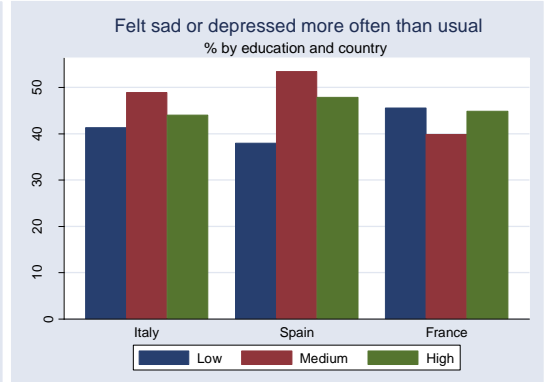

Panel f
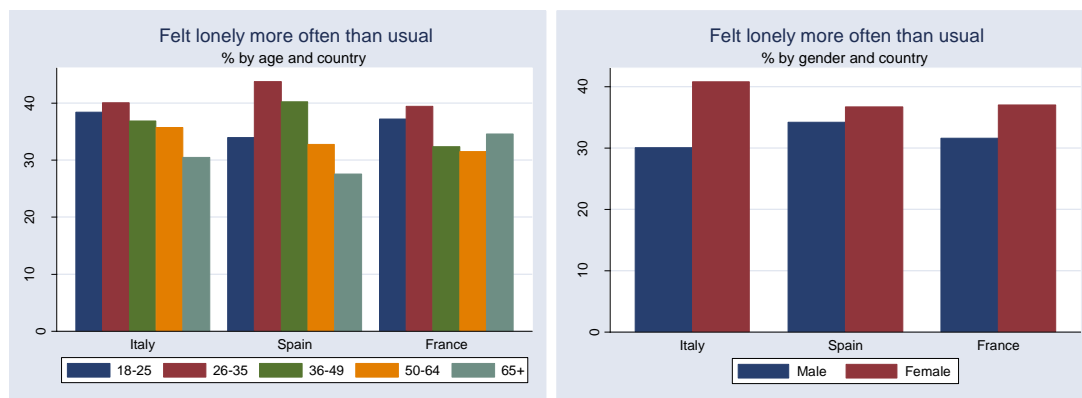

Felt lonely more often than usual

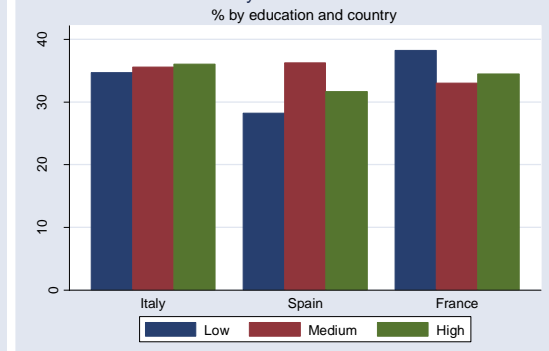

Note: $\mathrm{N}=9,056$. Post-stratification weights are used.

Source: Intergen-covid online survey. Data were collected between14-24 April 2020. 
Figure 7. Events experienced during the COVID-19 pandemic by country, demographic and socio-economic characteristics

Panel a

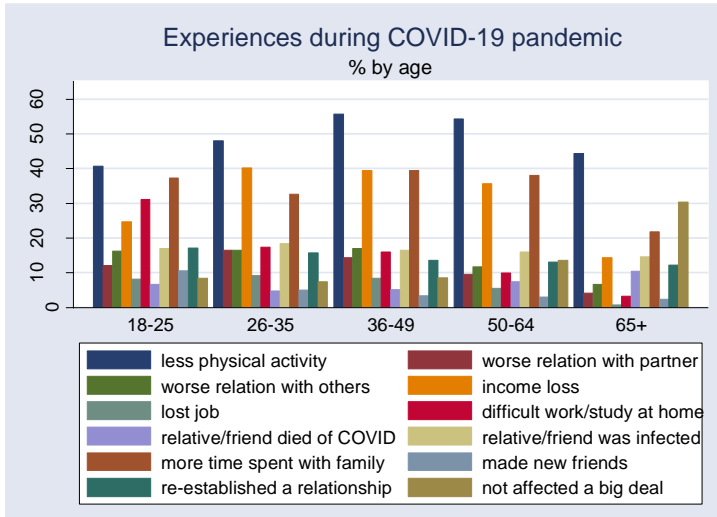

Panel c

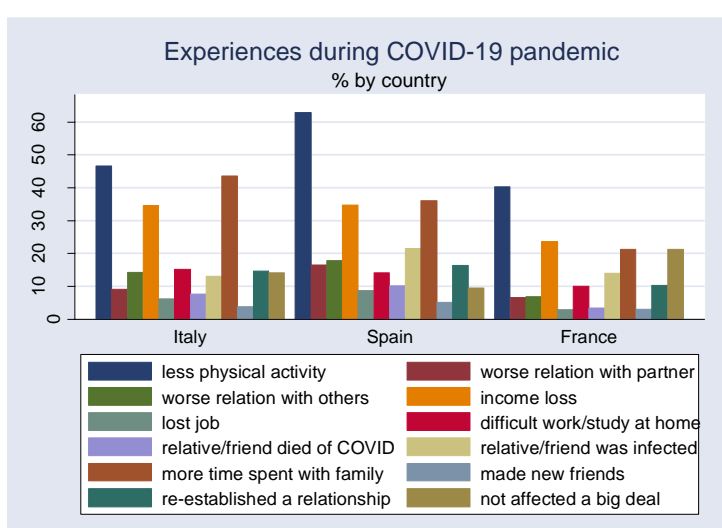

Panel b

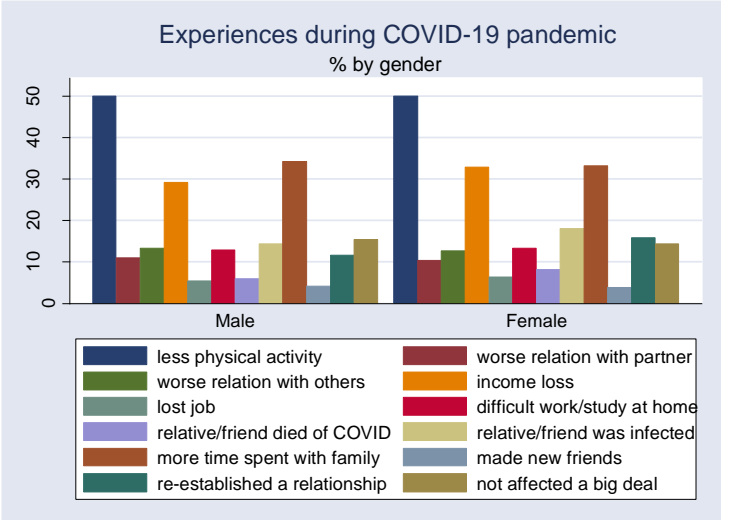

Panel d

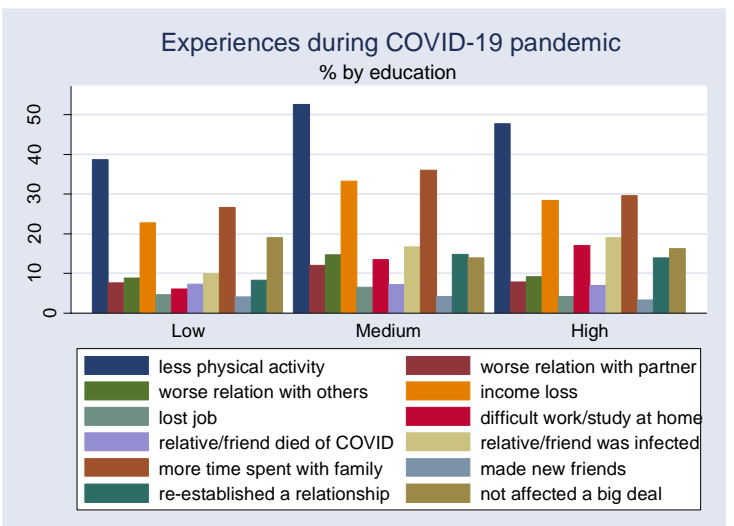

Note: $\mathrm{N}=9,056$. Post-stratification weights are used.

Source: Intergen-covid online survey. Data were collected between14-24 April 2020. 
Figure 8. Help and support received during the COVID-19 pandemic by country, demographic and socioeconomic characteristics

Panel a

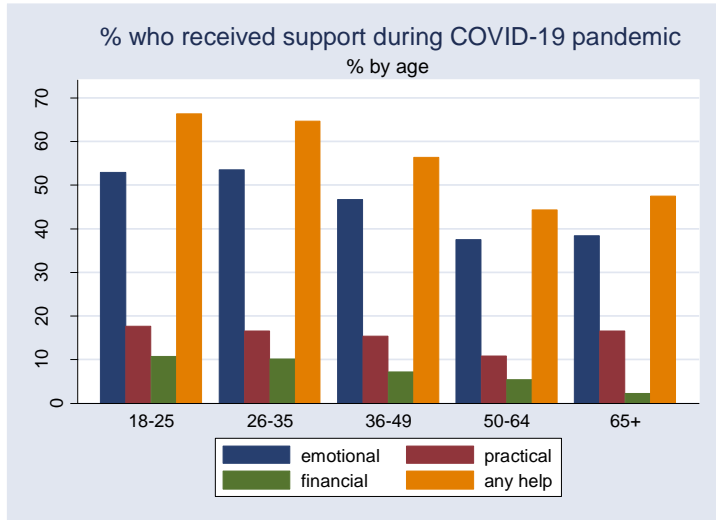

Panel c

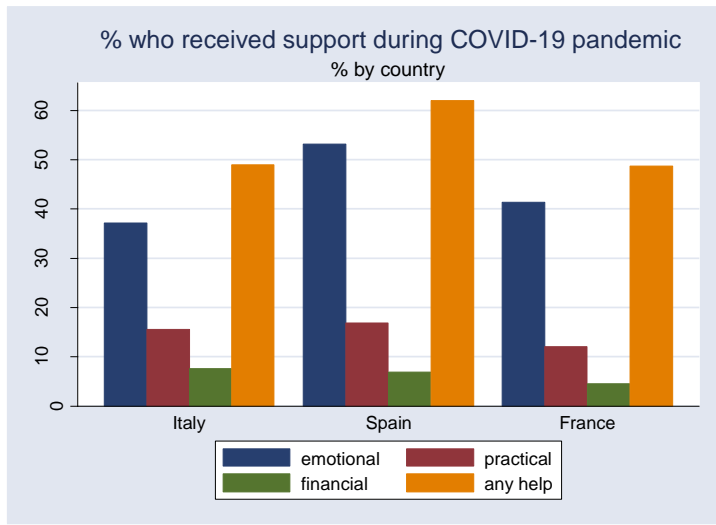

Panel b

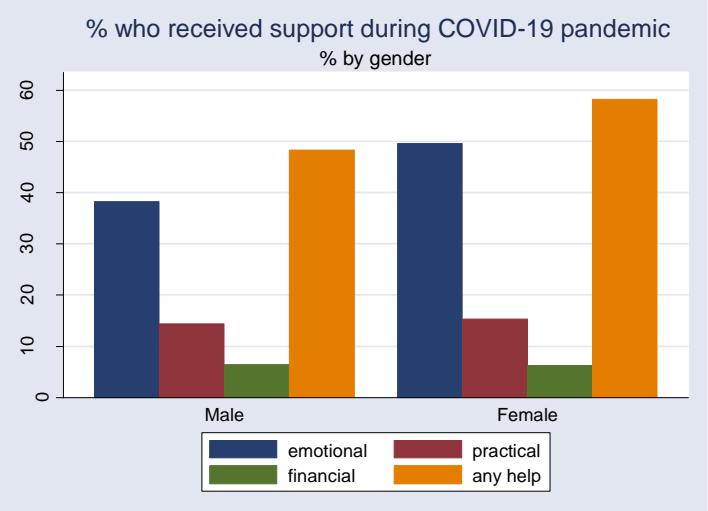

Panel d

$\%$ who received support during COVID-19 pandemic $\%$ by education

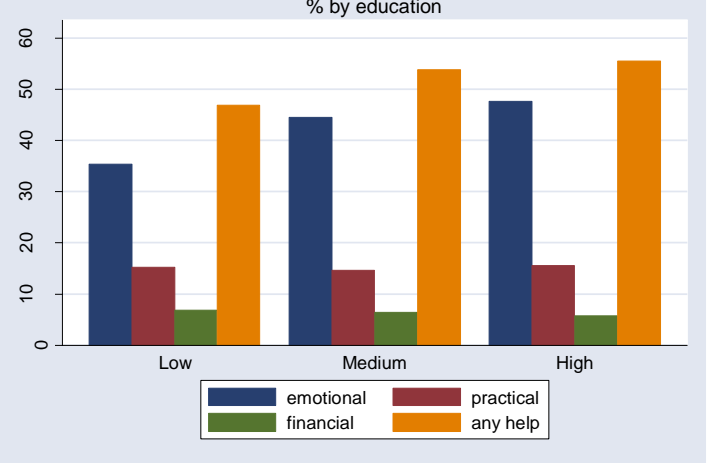

Note: $\mathrm{N}=9,056$. Post-stratification weights are used.

Source: Intergen-covid online survey. Data were collected between14-24 April 2020. 


\section{Appendix}

\section{Questionnaire - English version}

\section{Part A - Basic info on relations}

A.1) Which of the following family members do you have alive? (Tick all that apply)

- $\quad$ one or more children aged 0-3

- $\quad$ one or more children aged 4-16

- $\quad$ one or more children older than 16

- a partner

- one or more grandchildren

- father

- mother

- one or more grandparent

- other relatives (e.g. siblings)

- none

A.2) Before the emergence of the first cases of Coronavirus in your country (date), with whom were you usually living in the same house? (Tick all that apply)

- $\quad$ one or more children aged 0-3

- $\quad$ one or more children aged 4-16

- $\quad$ one or more children older than 16

- partner

- one or more grandchildren

- mother and/or father

- one or more grandparent

- other relatives (e.g. siblings)

- other persons (e.g. a friend, a flat mate)

- I used to live alone

A.3) After the emergence of the first cases of Coronavirus in your country (date), did you experience a change with respect to the people with whom you used to live with? (More than one option is allowed)

- No 
- Yes, I moved to my parents' house

- Yes, I moved to one of my children's house

- Yes, I moved to someone else's house

- Yes, one or both of my parents moved to my house

- Yes, one or more of my children moved to my house

- Yes, other people moved to my house

\section{Part B - Contacts}

B.1) Considering non-coresident persons only, before the entry into force of the first nationwide restrictions due to the Coronavirus in your country (date), with whom did you usually have frequent (at least once a week) contacts in person? (Tick all that apply)

- $\quad$ children ( 1 or more)

- grandchildren (1 or more)

- mother and/or father

- grandparents (1 or more)

- other relatives (e.g. siblings)

- friends (1 or more)

- nobody

B.2) Considering non-coresident persons only, since the entry into force of the first nationwide restrictions due to the Coronavirus in your country (date), with whom did you increase the frequency of contacts in person? (Tick all that apply)

- $\quad$ children (1 or more)

- grandchildren (1 or more)

- mother and/or father

- grandparents (1 or more)

- other relatives (e.g. siblings)

- $\quad$ friends (1 or more)

- I did not experience an increase in contacts in person with non-coresident persons

B.3) Considering non-coresident persons only, since the entry into force of the first nationwide restrictions due to the Coronavirus in your country (date), with whom did you decrease the frequency of contacts in person? (Tick all that apply)

- $\quad$ children (1 or more) 
- grandchildren (1 or more)

- mother and/or father

- grandparents (1 or more)

- other relatives (e.g. siblings)

- friends (1 or more)

- I did not experience a decrease in contacts in person with non-coresident persons

B.4) Considering non-coresident persons only, since the entry into force of the first nationwide restrictions due to the Coronavirus in your country (date), with whom did you have frequent (at least once a week) non-physical contacts (e.g. on the phone)? (Tick all that apply)

- $\quad$ children (1 or more)

- grandchildren (1 or more)

- mother and/or father

- grandparents (1 or more)

- other relatives (e.g. siblings)

- friends (1 or more)

- nobody in particular

B.5) Considering non-coresident persons only, since the entry into force of the first nationwide restrictions due to the Coronavirus in your country (date), with whom did you increase the frequency of non-physical contacts (e.g. on the phone)? (Tick all that apply)

- $\quad$ children (1 or more)

- grandchildren (1 or more)

- mother and/or father

- grandparents (1 or more)

- other relatives (e.g. siblings)

- friends (1 or more)

- I did not experience an increase in non-physical contacts with non-coresident persons

B.6) Considering non-coresident persons only, since the entry into force of the first nationwide restrictions due to the Coronavirus in your country (date), with whom did you decrease the frequency of non-physical contacts (e.g. on the phone)? (Tick all that apply)

- $\quad$ children (1 or more)

- grandchildren (1 or more) 
- mother and/or father

- grandparents (1 or more)

- other relatives (e.g. siblings)

- friends (1 or more)

- I did not experience a decrease in non-physical contacts with non-coresident persons

B.7) Considering non-coresident persons only, since the entry into force of the first nationwide restrictions due to the Coronavirus in your country (date), with whom did you have daily nonphysical contacts (e.g. on the phone)? (Tick all that apply)

- $\quad$ children (1 or more)

- grandchildren (1 or more)

- mother and/or father

- grandparents (1 or more)

- other relatives (e.g. siblings)

- friends (1 or more)

- nobody

B.8) Considering non-coresident persons only, since the entry into force of the first nationwide restrictions due to the Coronavirus in your country (date), with whom did you do/receive video calls? (Tick all that apply)

- $\quad$ children (1 or more)

- grandchildren (1 or more)

- mother and/or father

- grandparents (1 or more)

- other relatives (e.g. siblings)

- friends (1 or more)

- nobody

B.9) Considering non-coresident persons only, compared to before the entry into force of the first nationwide restrictions due to the Coronavirus in your country (date), did the frequency of video calls you do/receive change? (Only one option allowed)

- It increased

- It remained more or less the same

- It decreased 
- I started doing/receiving video calls, I never did it before the start of the pandemic

- I never did video calls

B.10) Considering non-coresident persons only, since the entry into force of the first nationwide restrictions due to the Coronavirus in your country (date), with whom did you exchange instant messages (e.g. via WhatsApp or other internet applications)? (Tick all that apply)

- $\quad$ children (1 or more)

- grandchildren (1 or more)

- mother and/or father

- grandparents (1 or more)

- other relatives (e.g. siblings)

- friends (1 or more)

- nobody

B.11) Considering non-coresident persons only, compared to before the entry into force of the first nationwide restrictions due to the Coronavirus in your country (date), did the frequency of exchange of instant messages (via e.g. WhatsApp or other internet applications) change? (Only one option allowed)

- It increased

- It remained more or less the same

- It decreased

- I started using instant messaging apps, I never did it before the start of the pandemic

- I never used instant messaging apps

B.12) Considering non-coresident persons only, since the entry into force of the first nationwide restrictions due to the Coronavirus in your country (date), with whom did you interact on the social media (e.g. Facebook)? (Tick all that apply)

- $\quad$ children (1 or more)

- grandchildren (1 or more)

- mother and/or father

- grandparents (1 or more)

- other relatives (e.g. siblings)

- friends (1 or more)

- nobody 
B.13) Considering non-coresident persons only, compared to before the entry into force of the first nationwide restrictions due to the Coronavirus in your country (date), did the frequency of interactions with other people on the social media (e.g. Facebook) change? (Only one option allowed)

- It increased

- It remained more or less the same

- It decreased

- I started using social media, I never did it before the start of the pandemic

- I never used social media

\section{Part C-Mental health}

C.1) During the past week, have you experienced most of the time or often any of the following items? (Tick all that apply)

- I felt that I could not shake off the blues even with help from my family or friends

- I felt depressed

- I thought my life had been a failure

- I felt fearful

- I felt lonely

- I had crying spells

- I felt sad

- I experienced some of the items above but only sometime or rarely

- I did not experience the items above at all

C.2) Compared to before the entry into force of the first nationwide restrictions due to the Coronavirus in your country (date), have you felt sad or depressed more or less than usual? (Only one option allowed)

- More often than usual

- About the same as usual

- Less often than usual

- I never felt sad or depressed 
C.3) During the past week, have you felt lonely: (Only one option allowed)

- Rarely or none of the time (e.g. less than 1 day)

- Some or a little of the time (e.g. 1-2 days)

- Occasionally or a moderate amount of time (e.g. 3-4 days)

- $\quad$ All of the time (e.g. 5-7 days)

C.4) Compared to before the entry into force of the first nationwide restrictions due to the Coronavirus in your country (date), have you felt lonely more or less than usual? (Only one option allowed)

- More often than usual

- About the same as usual

- Less often than usual

- I never felt lonely

\section{Part D-Risk and time preferences}

D.1) How do you see yourself: are you a person who is generally willing to take risks, or do you try to avoid taking risks? Please use a scale from 0 to 10 , where a 0 means you are "completely unwilling to take risks" and a 10 means you are "very willing to take risks". You can also use the values inbetween to indicate where you fall on the scale. (Only one option allowed)

- 0 (completely unwilling to take risks)

$-1$

$-2$

$-3$

$-4$

$-5$

$-6$

$-7$

$-8$

$-9$

- 10 (very willing to take risks)

D.2) Are you a person who is generally willing to give up something today in order to benefit from that in the future or are you not willing to do so? Please use a scale from 0 to 10 , where a 0 means you are "completely unwilling to give up something today" and a 10 means you are "very willing to 
give up something today". You can also use the values in-between to indicate where you fall on the scale. (Only one option allowed)

- $\quad 0$ (completely unwilling to give up something today)

$-1$

$-2$

$-3$

$-4$

$-5$

$-6$

$-7$

$-8$

$-9$

- 10 (very willing to give up something today)

Part E-Experiences during Coronavirus and intentions for next three years

E.1) Since the entry into force of the first nationwide restrictions due to the Coronavirus in your country (date), have you experienced any of these changes? (Tick all that apply)

- reduction in physical activity

- worsened relation with partner

- worsened relation with other people

- $\quad$ suffered income loss

- lost job

- difficulties with organizing work or study from home

- death of a relative or friend due to Coronavirus

- a relative or friend was infected

- had more time to spend with family

- made new friends

- re-established a relationship with a relative or friend

- my life was not affected a big deal

- none of the above

E.2) Since the entry into force of the first nationwide restrictions due to the Coronavirus in your country (date), have you received any help or support? (Tick all that apply)

- Yes, understanding and emotional support from family and/or friends 
- Yes, understanding and emotional support from unfamiliar persons (such as neighbor) or organizations

- Yes, practical help (e.g., with shopping or cooking) from family and/or friends

- Yes, practical help (e.g., with shopping or cooking) from unfamiliar persons (such as neighbor) or organizations

- Yes, financial help from family and/or friends

- Yes, financial help from unfamiliar persons (such as neighbor) or organizations

- I have not received help or support

E.3) Within the next three years... (Tick all options among those that may apply to your situation)

- I definitely intend to exit the parental home

- I definitely DO NOT intend to exit the parental home

- I definitely intend to start a cohabitation with my partner

- I definitely DO NOT intend start a cohabitation with my partner

- I definitely intend to marry my partner

- I definitely DO NOT intend to marry my partner

- I definitely intend to have or to adopt a/another child

- I definitely DO NOT intend to have or to adopt a/another child

- I definitely intend to divorce / separate from my partner

- I definitely DO NOT intend to divorce / separate from my partner

- I definitely intend to give up paid work

- I definitely DO NOT intend to give up paid work

- None of the above

\section{Part F - Socio-demographics and general health}

F.1) In what year were you born?

F.2) What is your sex?

- Female

- Male

- Other

F.3) Before the emergence of the first cases of Coronavirus in your country (date), in what region were you usually living? 
(To be chosen from a drop-down menu - Including “Abroad”)

F.4) Since the emergence of the first cases of Coronavirus in your country (date), in what region have you been usually living?

(To be chosen from a drop-down menu - Including “Abroad”)

F.5) Which phrase on this card best describes the area where you live?

- A big city

- The suburbs or outskirts of a big city

- A town or a small city

- A country village

- A farm or home in the countryside

F.6) What is your current marital status?

- Single

- Married or in a legal union

- In a romantic relationship and living with my partner (cohabiting)

- In a romantic relationship but not cohabiting with my partner

- Separated or divorced

- Widowed

F.7) What is the highest level of education you have achieved? (adapted in each country)

- No qualifications

- CSE grade 2-5/GCSE grades D-G or equivalent

- CSE grade 1/O-level/GCSE grades A-C or equivalent

- A-level, AS-level or equivalent

- Degree/postgraduate qualification or equivalent

- $\mathrm{PhD}$

F.8) Which of these descriptions best describes your employment situation before the entry into force of the first nationwide restrictions due to the Coronavirus in your country (date)? 
- in paid work (or away temporarily) (employee, self-employed, working for your family business)

- in education, even if on vacation (not paid for by employer)

- unemployed

- permanently sick or disabled

- retired

- in community or military service

- doing housework, looking after children or other persons

- other

F.9) Which of the following descriptions comes closest to how you feel about your income nowadays?

- Living comfortably on present income

- Coping on present income

- Finding it difficult on present income

- Finding it very difficult on present income

F.10) How would you rate, on average, your health before the entry into force of the first nationwide restrictions due to the Coronavirus in your country (date)?

- Very good

- Good

- Fair

- Poor

- Very Poor

F.11) Do you have any long-standing illness or chronic condition?

- Yes

- No 